\title{
STUDY OF DRYING AND REHYDRATION KINETICS OF CARROT CYLINDERS
}

\author{
Tatjana Rubina $^{1}$, Aivars Aboltins ${ }^{1}$, Janis Palabinskis ${ }^{1}$, Egle Jotautiene ${ }^{2}$ \\ ${ }^{1}$ Latvia University of Life Sciences and Technologies, Latvia; \\ ${ }^{2}$ Aleksandras Stulginskis University, Lithuania \\ tatjana.rubina@1lu.lv, aivars.aboltins@inbox.lv, janis.palabinskis@1lu.lv, egle.jotautiene@asu.lt
}

\begin{abstract}
Product drying is the most popular method of product preservation in the food industry, while rehydration is a process that results in restoration of the properties of the product. During the carried out study characteristics of drying and rehydration were examined. The aim of this study was to investigate drying and rehydration characteristics and experimentally determine the changes of sample dimensions of carrot cylinders during drying and rehydration processes. Cylindrical carrot samples of $10 \mathrm{~mm}$ and $15 \mathrm{~mm}$ diameter were cut using stainless steel die. Prior to rehydration the samples were dried in a convective oven at temperature $40{ }^{\circ} \mathrm{C}$ for 24 hours in laboratory conditions. Samples were weighed during the first 6 hours and at the end of the experiment. At specified time intervals the diameter and shrinkage were examined. The dried carrot samples were then rehydrated in a water bath at temperature $23{ }^{\circ} \mathrm{C}$ for 24 hours. The weight of the samples was examined at specified time intervals over the first 6 hours and additional measurement of a diameter and thickness at the end of the experiment was performed. Results of this study showed that thickness of carrot cylinders decreases 1.8 times during the drying process, but after the rehydration process the thickness size returns up to $93 \%$, while the diameter changes are smaller in both processes. As a result of drying, the diameter changes by $35 \%$, but after rehydration its size returns to $82 \%$. As a result of drying carrot samples lose $87 \%$ of their weight for 24 hours, but after rehydration for the same time about $40 \%$ of their initial weight returns. Besides, about $70 \%$ of the recovered weight returns during the first 3 hours of rehydration. Results of this study can be used for modelling purposes of drying and rehydration characteristics of carrot cylinders.
\end{abstract}

Keywords: carrot, drying, rehydration, shrinkage.

\section{Introduction}

In several few years the European Union (EU) citizens are increasingly focusing on their health. One of the great products of a healthy lifestyle is a carrot. Carrots are rich in beta-carotene, vitamins A, C, and D, iron and calcium. Carrots contain 6 times more calcium than potatoes and have relatively higher antioxidant content. According to the data provided in website of the EU statistical office called Eurostat [1], in the EU totally were produced 5,593.6 thousand tons (th.t.) of carrots in 2016. Further, the main producers in the EU were Poland (822 th.t., $14.7 \%$ ), the United Kingdom (723 th.t., $12.9 \%$ ), Germany (641.6 th.t., $11.5 \%$ ), the Netherlands (600.4 th.t., $10.7 \%$ ) and France (578.5 th.t., $10.3 \%$ ). In 2016 the Baltic States, Latvia, Lithuania and Estonia take the places 24, 19 and 26 accordingly in the EU producers rating with their contribution 14.8, 43.0 and 11.1 thousand tons of carrots.

To enhance the storage life of agricultural products drying is applied. Drying is the most popular method of food preservation, during which water is removed up to a certain level, microbial activity is minimized and the product is relatively chemically stable [2;3]. Food drying provides an opportunity to minimize losses during storage [4], save transportation and shipping costs [5;6]. Several studies were performed to examine characteristics of different drying methods such as sun drying [5], convective drying [2], microwave drying [7; 8], vacuum [9] and freeze-drying [10; 11]. Other researches were focused on the effect investigation of different pre-treatments $[12 ; 13]$ and pretreatment methods, for example blanching [14], in order to prevent the loss of colour, become a good quality product and reduce the drying time. As Doymaz argues [5], the most common and commercially used pre-treatments are potassium and sodium hydroxide, potassium carbonate and meta bisulphate, methyl and ethyl ester emulsion, ascorbic and citric acids.

Prior the use dehydrated products are usually rehydrated and show similar characteristics to the fresh product [15]. During the rehydration process the properties of the product are restored. As VegaGalvez et al. [15] note, rehydration can be considered as a measure of the damage to the product caused by the drying process. Several studies were performed to estimate characteristics of rehydration $[3 ; 5 ; 16]$. Other studies were related with estimation of several factor influence on the rehydration process such as drying pre-treatments [17], techniques, conditions, temperature [15], and composition of the immersion media. 
The aim of this study was to investigate drying and rehydration characteristics and experimentally determine the changes of sample dimensions of carrot cylinders during drying and rehydration processes.

\section{Materials and methods}

Food material. The research object is a carrot, which was purchased at a local market in Jelgava. A cylindrical carrot samples of $25 \mathrm{~mm} \pm 0.5 \mathrm{~mm}$ diameter with two different thickness $10 \mathrm{~mm}$ (Fig.1. a)) and $15 \mathrm{~mm}$ were cut using a stainless steel die and cylindrical tube.

Experiment procedure. Before the drying process measurement of the sample dimensions was made using the Digital Caliper 1103 with measurement accuracy $\pm 0.01 \mathrm{~mm}$. The carrot samples were dried in a convective oven Memmert at $40{ }^{\circ} \mathrm{C}$ for 24 hours (Fig.1. b)). The samples were regularly weighted using the laboratory balance Kern EW 1500-2M with measurement accuracy $\pm 0.01 \mathrm{~g}$ at specified time intervals during the drying process. At the end of the drying process measurement of the sample dimensions was made.

The initial moisture amount was determined using the amount of the product dry mass or basis (db) that was obtained according to the methodology described by Rubina et al. [18].

The dried carrot samples were then rehydrated by immersion in distilled water with temperature $23{ }^{\circ} \mathrm{C} \pm 1{ }^{\circ} \mathrm{C}$. At specified time intervals the samples were removed from the water bath, blotted with tissue paper to remove superficial water and weighted. The measurements of rehydration characteristics were examined over 7 hours (Fig.1. c)). After 22 hours an additional measurement of the sample weight and dimensions was taken.

a)

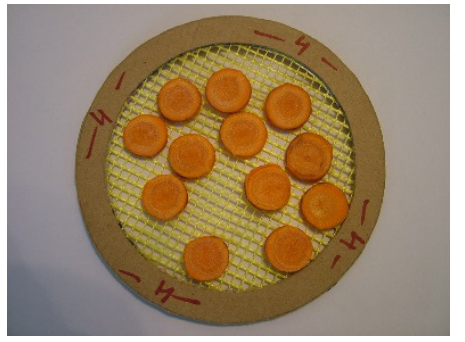

b)

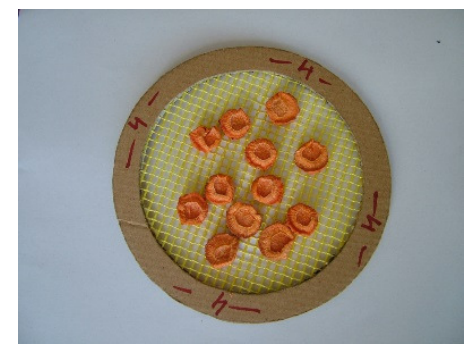

c)

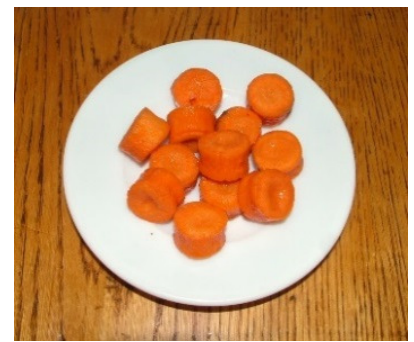

Fig. 1. Carrot sample: $\mathrm{a}$ - before drying; $\mathrm{b}$ - after drying; $\mathrm{c}$ - after rehydration

Mathematical modelling. The moisture content of drying a sample at time $t$ can be transformed to be the moisture ratio (MR) [5] and was calculated using equation (1):

$$
M R=\frac{M_{t}-M_{\infty}}{M_{0}-M_{\infty}},
$$

where $M_{t}-$ moisture content at any time of drying, g;

$M_{0}$ - initial moisture content, g;

$M_{\infty}$ - equilibrium moisture content, $\mathrm{g}$.

The drying coefficient value at time $t$ can be calculated using the formula (2) described by Aboltins and Upitis [19]:

$$
K=-\frac{\ln \left(\frac{M_{t}-M_{\infty}}{M_{0}-M_{\infty}}\right)}{t_{i}},
$$

where $t_{t}$-drying time, $\mathrm{h}$.

The diffusion coefficient at each time moment $t$ can be expressed using equation (3) described by Rubina et al. [18]:

$$
D=\frac{K_{t} L^{2}}{\pi^{2}},
$$

where $K_{t}-$ drying coefficient at any time, $\mathrm{h}^{-1}$; 
$L-$ thickness of carrot slices, $\mathrm{mm}$.

The rehydration ratio was calculated using equation (4) used by Doymaz [5], Cunningham [2] and [20]:

$$
R R=\frac{M_{R t}}{M_{D}},
$$

where $M_{R t}-$ weight of rehydrated sample at any time, $\mathrm{g}$;

$M_{D}$ - weight of dried sample, $\mathrm{g}$.

The analysis of the experimental data was performed using descriptive statistics and regression analysis. Using the experimental data and performing the regression analysis the average thickness of the sample slices and average diameter dependence on the drying (rehydration) time were determined.

Linear and exponential regression equations, as well as the determination coefficient (R2) were determined using Microsoft Excel built in facilities.

\section{Results and discussion}

Two series of measurements concerning drying of carrot cylinders were taken: $10 \mathrm{~mm}$ thick and $15 \mathrm{~mm}$ thick sliced carrot cylinders with an average diameter of $25 \mathrm{~mm} \pm 0.5 \mathrm{~mm}$.

The ratio evolution of present moisture for $10 \mathrm{~mm}$ and $15 \mathrm{~mm}$ thick cylinders with confidential interval $(P=95 \%)$ during the drying process, expressed in $\mathrm{g}$ of water per $\mathrm{g}$ of dry basis $\left(\mathrm{g} \mathrm{H}_{2} \mathrm{O} / \mathrm{g} \mathrm{db}\right)$ is presented in Fig. 2. The scattered points show the average value of the moisture ratio, but the continuous line indicates the obtained theoretical law that describes the changes of the concentration ratio in drying time. The dynamic changes of the moisture ratio have exponential character.

The obtained results show that average moisture ratio was $0.888 \pm 0.005$ for $15 \mathrm{~mm}$ thick carrot cylinders and 0.932 for $10 \mathrm{~mm}$ thick carrot cylinders before the drying experiment. During the drying experiment after the first approximately 5 hours average moisture ratio decreases down to $0.502 \pm 0.057$ and $0.638 \pm 0.031(P=95 \%)$, accordingly. But after 20 hours of drying it decreases to $0.07 \pm 0.025$ and $0.289 \pm 0.019$ in carrot cylinders with the previously mentioned thicknesses appropriately.

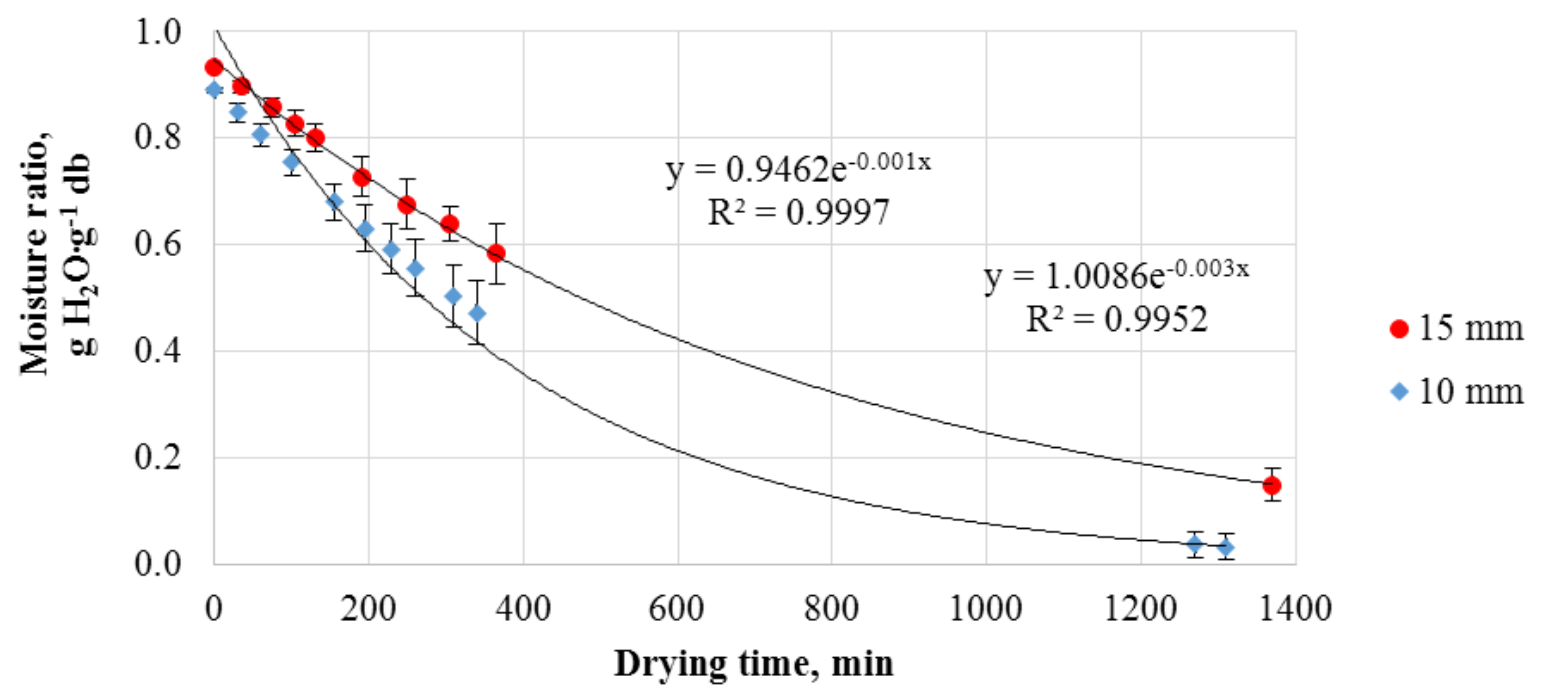

Fig. 2. Drying curves of carrot samples

Evolution of the measured diffusion coefficient considering shrinkage changes in fibber direction (thickness) during the drying process, expressed in square millimetres per hour, is presented in Fig. 3. The scattered points indicate the values of the diffusion coefficient and the continuous line represents the linear regression of the type (5):

$$
D=k_{0} t+k_{1},
$$


where $D$-drying coefficient in $\mathrm{mm}^{2} \cdot \mathrm{h}^{-1}$;

$t$ - drying time, $\mathrm{h}$;

$k_{0}, k_{1}$ - regression coefficients.

The results show that the changes of the diffusion coefficient values (Fig. 3.) depend linearly on the drying time similarly for cylinders of both thicknesses. In addition, consideration of the thickness changes results in the values of the diffusion coefficient decreasing during the drying experiment.

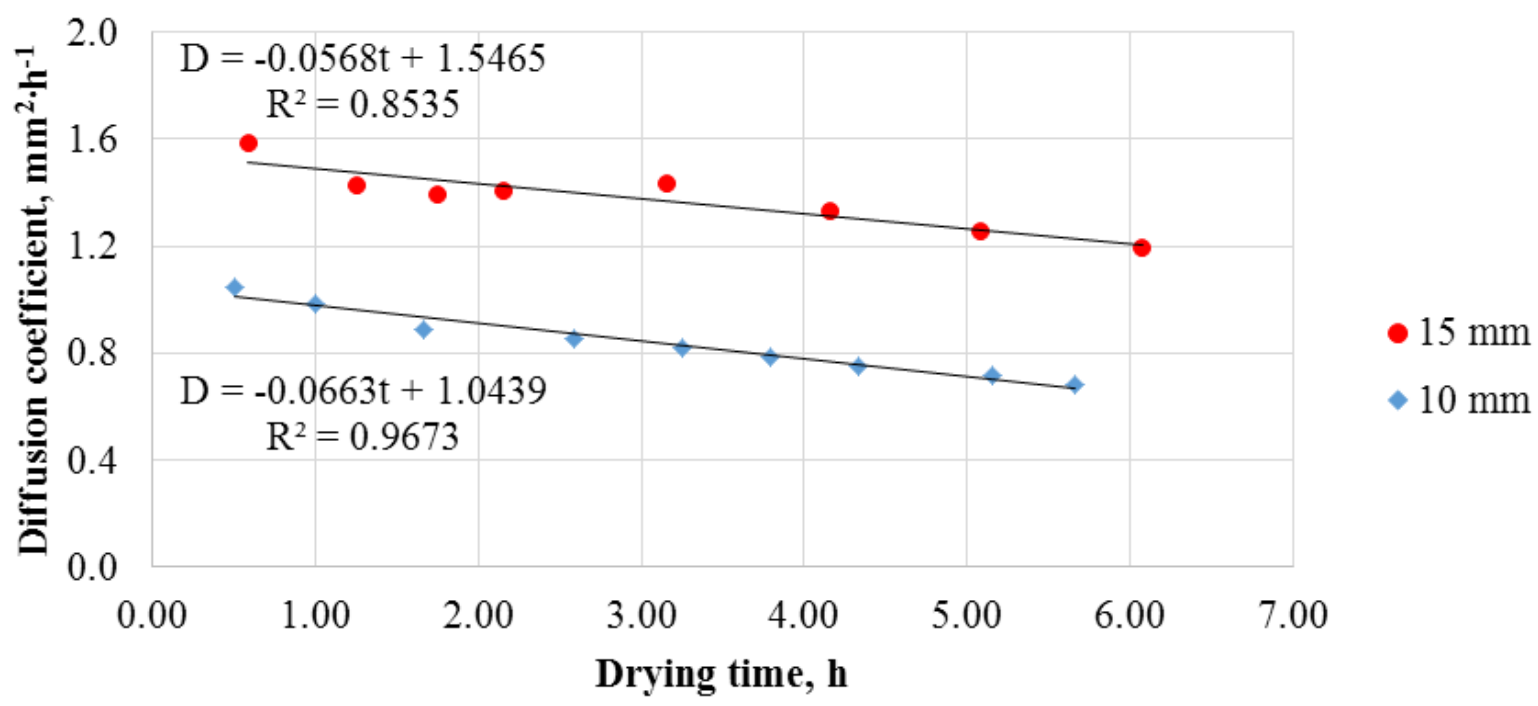

Fig. 3. Diffusion coefficient dependence on drying time

Fig.4. shows evolution of rehydration ratio in time. As the results indicate, thinner samples uptake water faster than thicker samples with the approximate ratio of two thirds after one hour from beginning of the experiment and further. After 1 hour of rehydration the weight of $10 \mathrm{~mm}$ thick carrot cylinders increases more than 3 times, while the weight of $15 \mathrm{~mm}$ thick samples - a little more than 2 times. After 6 hours of the rehydration experiment the weight of $15 \mathrm{~mm}$ thick carrot cylinders increases a little more than 3 and a half times, but in case of $10 \mathrm{~mm}$ thick samples the weight increases approximately 5 and a half times. Similar results were obtained in case of blanched apple slices by Doymaz [5].

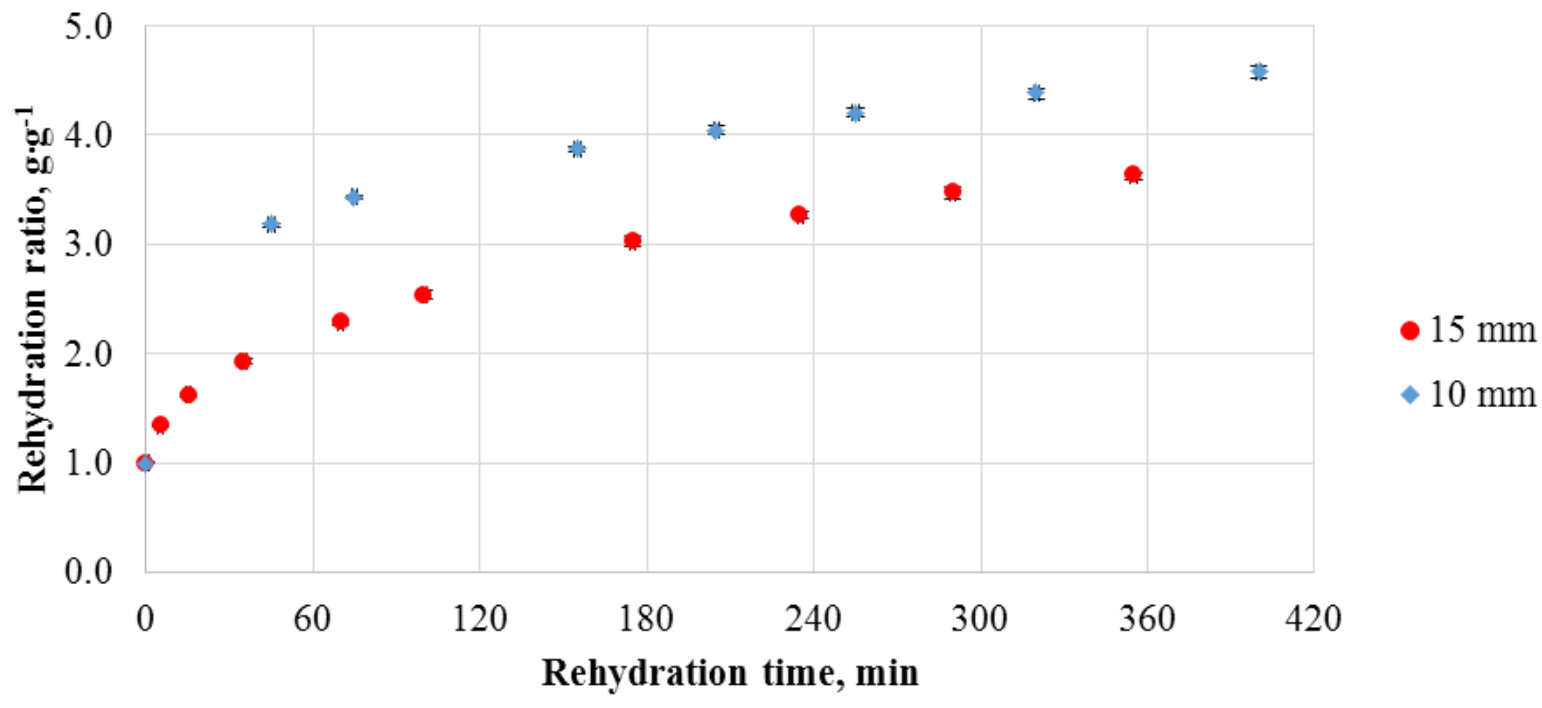

Fig. 4. Rehydration curves of carrot samples

As the experimental data indicate, shrinkage changes in the fiber and in the side direction take place during drying and rehydration processes. Fig.5. shows the changes of average diameter, expressed in mm during the drying process and after rehydration. After 20 hours of drying the average diameter decreases one and a half times with the value $16.34 \pm 0.91 \mathrm{~mm}(P=95 \%)$ and constitutes 
$65.4 \%$ of the initial diameter. After almost 23 hours of rehydration the average diameter has recovered reaching the value $20.43 \pm 0.55 \mathrm{~mm}(P=95 \%)$ and constitutes $81.2 \%$ of the initial diameter.

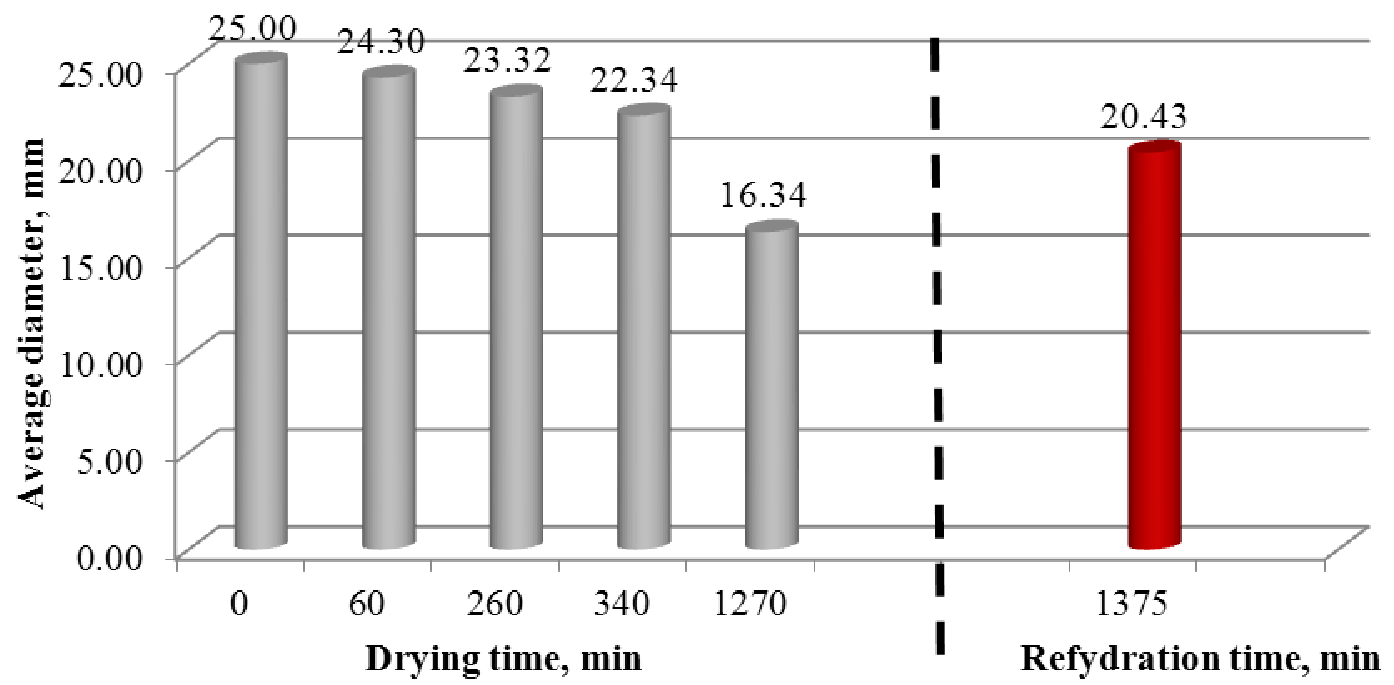

Fig. 5. Average diameter changes of carrot samples with thickness $10 \mathrm{~mm}$ during drying process and after rehydration

In case of shrinkage changes in the fiber direction (Fig. 6.), the situation is sharper. Comparing the initial thickness with it after 20 hours of drying, the thickness has become 1.85 times smaller with the value $5.56 \pm 0.82 \mathrm{~mm}(P=95 \%)$ and constitutes $54.1 \%$ of the initial thickness. But after 23 hours of rehydration it has recovered reaching the value $9.64 \pm 0.41 \mathrm{~mm}(P=95 \%)$ that constitutes $93.9 \%$ of the initial thickness.

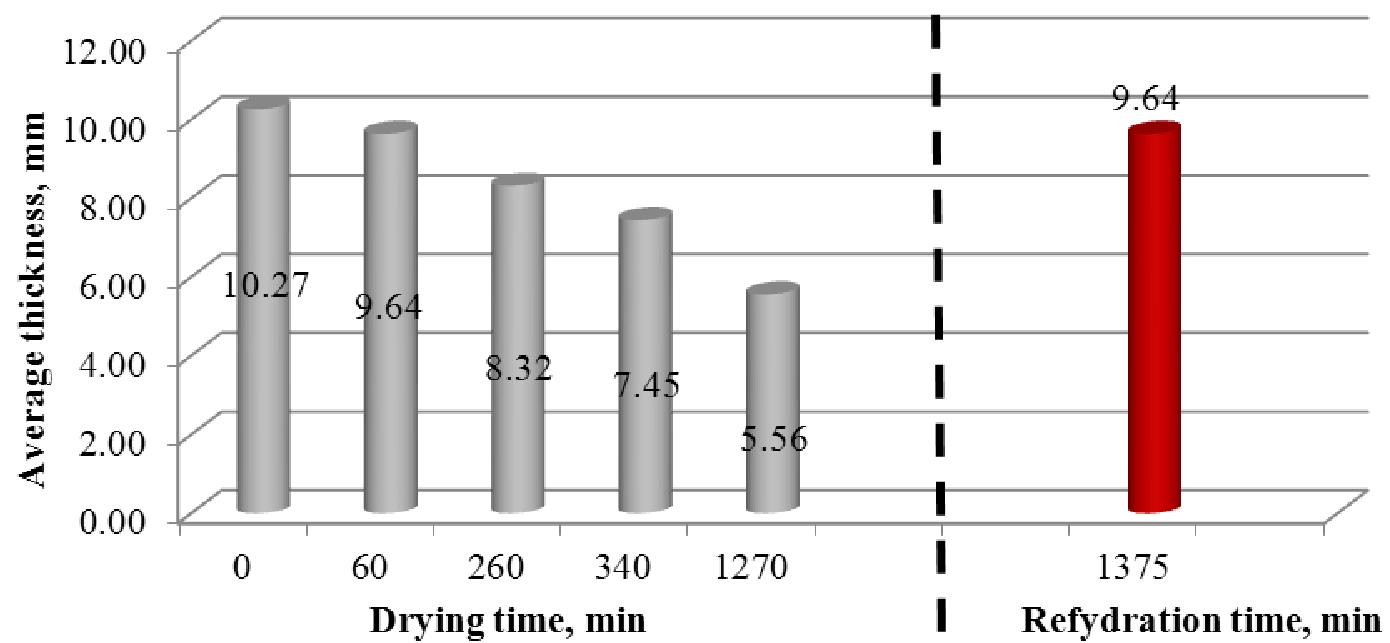

Fig. 6. Changes of average thickness of carrot samples with thickness $10 \mathrm{~mm}$ during drying and after rehydration process

\section{Conclusions}

1. Study results show that the changes of shrinkage in the fiber and in the side directions differ. The thickness of the samples becomes smaller up to 1.8 times during the drying process, while the diameter decreases 1.5 times. Moreover, the thickness recovers more than $93 \%$ of its initial size during the rehydration process, while the diameter of carrot cylinders recovers about $82 \%$ during the same time. As a result of drying carrot samples lose $87 \%$ of their weight for 24 hours, but 
after rehydration for the same time about $40 \%$ of their initial weight returns. Besides, about $70 \%$ of the recovered weight returns during returns first 3 hours of rehydration.

2. Taking into account the thickness changes, it became possible to describe more precisely the diffusion process and diffusion coefficient dependence on other parameters, such as the drying time and moisture concentration. The study has shown that, in theoretical description, modelling of the drying process must take into account the dimensional changes in the product itself during the drying process.

\section{References}

[1] Eurostat. Agricultural production - crops. 2017. [online] [03.03.2018]. Available at: http://ec.europa.eu/eurostat/statistics-explained/index.php/Agricultural_production_-_crops

[2] Cunninghman S.E., Mcminn W.A.M., Magee T.R.A. etc. Experimental study of rehydration kinetics of potato cylinders. Food and bioproducts processing, vol. 86, 2008, pp. 15-24.

[3] Krokida M.K., Marinos-Kouris D. Rehydration kinetics of dehydrated products. J Food Eng, vol. 57(1), 2003, pp. 1-7.

[4] Margaris D.P., Ghiaus A.-G. Fruits and vegetables dehydration in tray dryers. New Food Engineering Research Trends (Eds. Urwaye A.P.), 2008, pp.45-101.

[5] Doymaz I. Effect of citric acid and blanching pre-treatments on drying and rehydration of Amasya red apples. Food and bioproducts processing, vol. 88, 2010, pp. 124-132.

[6] Dikbasan T. Determination of the effective parameters for drying of apples. A Master degree thesis in Energy Engineering, 2007, 91 p.

[7] Khraisheh M.A.M., Mcminn W.A.M., Magee T.R.A. Quality and structural changes in starchy foods during microwafe and convective drying. Food Res Int, vol. 37(5), 2004, pp. 497-503.

[8] Funebo T., OhlssonT. Microwave-assisted air dehydration of apple and mushroom. J Food Eng, vol. 38(3), 1998, pp. 353-367.

[9] Lee J.H., Kim H.J. Vacuum drying kinetics of Asian white radish (Raphanus sativus L.) slices. LWT Food Sci.Technol., vol. 42, 2009, pp. 180-186.

[10] Vergeldt F.J., van Dalen G., Duijster A.J. etc. Rehydration kinetics of freeze-dried carrots. Innovative Food Science \& Emerging Technologies, 2014, 8 p.

[11]Benseddik A., Azzi A., Zidoune M.N. etc. Empirical and Diffusion Models of Rehydration Process of Differently Dried Pumpkin Slices. Journal of the Saudi Society of Agricultural Sciences, 2018. $33 \mathrm{p}$.

[12] Marguez-Rios E., Ocano-Higuera V.M., Maeda-Martinez A.N. etc. Citric acid as pretreatment in drying of Pacific Lion's Paw Scallop (Nodipecten subnodosus) meats. Food Chem., vol. 112, 2009, pp.599-603.

[13] Kingsly R.P., Goyal R.K., Manikantan M.R. etc. Effects of pretreatments and drying air temperature on drying behavior of peach slice. Int. J. Food. Sci., vol. 60, pp. 344-347.

[14] Tembo L., Chiteka Z.A., Kadzere I. etc. Blanching and drying period affect moisture loss and vitamin C content in Ziziphus mauritiana (Lamk.). Afr. J. Biotechnol., vol. 7, 2008, pp. 3100-3106.

[15] Vega-Galvez A., Notte-Cuello E., Lemus-Mondaca R. etc. Mathematical modelling of mass transfer during rehydration process of Aloe vera (Aloe barbadensis Miller). Food and bioproducts processing, vol. 87, 2009, pp. 254-260.

[16] Moreira R., Chelco F., Chaguri L. etc. Water absorption, texture and color kinetics of air-dried chestnuts during rehydration. J Food Eng., vol. 86(4), 2008, pp. 584-594.

[17] Taiwo K.A., Angersbach A., Knorr D. Rehydration studies on pretreated and osmotically dehydrated apple slices. J Food Sci., vol. 67(2), pp. 842-847.

[18] Rubina T., Aboltins A., Palabinskis J. etc. Potatoes drying dynamics research. Proceedings of International Scientific Conference Engineering for Rural Development, Latvia University of Agriculture, Jelgava, Latvia, 2016, pp. 187-192.

[19] Aboltins A., Upitis A. The mathematical model of carrot slices drying. Agricultural Engineering, vol. XXXVI(2), 2011, pp. 69-75.

[20] Lewicki P.P. Some remarks on rehydration of dried foods. J Food Eng., vol. 36(1), 1998, pp. 81-87. 